\title{
ANALYSIS OF FATIGUE CRACK GROWTH IN SHIP STRUCTURAL DETAILS
}

\author{
Heba W. Leheta \\ Ahmed M. H. Elhewy \\ Helmy A. Younes \\ Naval Architecture and Marine Engineering Department, Faculty of Engineering, \\ Alexandria University
}

\begin{abstract}
Fatigue failure avoidance is a goal that can be achieved only if the fatigue design is an integral part of the original design program. The purpose of fatigue design is to ensure that the structure has adequate fatigue life. Calculated fatigue life can form the basis for meaningful and efficient inspection programs during fabrication and throughout the life of the ship. The main objective of this paper is to develop an add-on program for the analysis of fatigue crack growth in ship structural details. The developed program will be an add-on script in a pre-existing package. A crack propagation in a tanker side connection is analyzed by using the developed program based on linear elastic fracture mechanics (LEFM) and finite element method (FEM). The basic idea of the developed application is that a finite element model of this side connection will be first analyzed by using ABAQUS and from the results of this analysis the location of the highest stresses will be revealed. At this location, an initial crack will be introduced to the finite element model and from the results of the new crack model the direction of the crack propagation and the values of the stress intensity factors, will be known. By using the calculated direction of propagation a new segment will be added to the crack and then the model is analyzed again. The last step will be repeated until the calculated stress intensity factors reach the critical value.
\end{abstract}

Keywords: Fatigue crack, linear elastic fracture mechanics (LEFM), finite element method (FEM)

\section{INTRODUCTION}

Although a ship may be designed to withstand the ultimate stresses imposed by heavy storm waves, failure could occur due to apparently low stresses generated by the continuously encountered smaller, although significant, ocean swells, as well as impact loads resulting from the routine loading and manoeuvring of a ship. When assuming that a ship has a life of 20 years and operates at sea for $75 \%$ of her life time, and knowing that the medium period of wave encounter is approximately equal to 5 seconds, the ship will experience nearly 100 million loading cycles throughout her life. Structural failure of a ship may result in consequences that range from simple leaks to severe loss of lives. The failure consequences are functions of the ship's age, the damaged component, its location, and the maintenance and repair history of the ship $[1,2]$

In the past, ship structure design often did not incorporate explicitly an analysis of fatigue. However, as stated in the subject-matter literature, the main reasons for interest to studying fatigue cracking is, in the last few years, the introduction of high tensile steels and the development of very large ships (e.g. VLCC, ULCC) which results in increasing the stresses in critical structural details and decreasing its fatigue life. Although the allowable stress methods are used in the design of majority of ship structures, more and more of the new designs incorporate detailed analysis methods. [3,4]

Fatigue failure avoidance is a goal that can be achieved only if the fatigue design is an integral part of the original design program. An improper design may lead to an unacceptable catastrophic fatigue failure resulting in loss of life and damage 
to the environment. Non-catastrophic fatigue failures are also unacceptable due to difficulty and cost of repairs as well as the need to increase costly inspection and maintenance intervals. The aim of fatigue design is to ensure that the structure has adequate fatigue life. Calculated fatigue life can also form basis for meaningful and efficient inspection programs during fabrication and throughout the life of the ship $[3,5]$.

The finite element method is a numerical procedure that can be applied to obtain solutions to a variety of engineering problems e.g. stress analysis, heat transfer, fluid flow, etc. Such problems may be steady, linear, or nonlinear ones. Yet, it was not until 1960 that Clough made the term "finite element" popular [6]. There are many finite element software packages available in the market however, most of them do not have a built- in function for fatigue analysis. The few that have a built -in function for fatigue analysis can be used to study fatigue crack propagation along a predefined path. For example, ABAQUS ver. 14 software package has either static crack analysis or crack propagation analysis but the crack propagation path must be known before the analysis. The case of predefined path crack analysis may be practical for the analysis of lamination cracks, e.g. in fibre glass composites. However, this feature cannot be used for crack in steel ship structural details where the crack path is unknown.

The aim of this paper is to evaluate fatigue analysis by using linear elastic fracture mechanics ( LEFM), and to achieve this aim an add-on program is developed to analyze fatigue crack growth in ship structural details. The program will be an add-on script in ABAQUS software. The application was developed by using python programming language which can be incorporated into ABAQUS to extend its features.

The fatigue analysis techniques are presented in the next section, where a summary on cumulative damage approach emphasizing linear cumulative damage approach (Miner's rule) is discussed. A detailed discussion of fracture mechanics especially linear elastic fracture mechanics, LEFM, is presented in Sec. 4. Also crack stages and stress intensity factors are discussed. The application of LEFM for fatigue analysis is given to show fatigue life calculation by using LEFM (Paris law).

\section{METHODS FOR FATIGUE ANALYSIS}

A broad view of the common methods for fatigue analysis is shown in Fig. 1 [7]. Fatigue analysis may be carried out by methods based on fatigue tests ( $\mathrm{S}-\mathrm{N}$ data) and estimation of cumulative damage (Miner rule). Another approach to fatigue analysis is fracture mechanics which is discussed in details in the following section, separately.

Predicting fatigue damage for structural components subjected to variable loading conditions is a complex issue. The first, simplest, and most widely used damage model is the linear damage. This rule is often referred to as Miner's rule (1945). However, in many cases the linear rule often leads to non-conservative life predictions. The results from this approach do not take into account the effect of load sequence on the accumulation of damage due to cyclic fatigue loading. Since the introduction of the linear damage rule many different fatigue damage theories have been proposed to improve the accuracy of fatigue life prediction $[3,8,9]$.

Ship structure design often did not include explicit treatment of fatigue by means of an analysis. However, with the increasing in using higher strength steels and the increased cyclic stress ranges, fatigue analysis of structures is increasingly required. Although the developed allowable stress methods ( which use S-N curves) are applied in the design of majority of ship structures, more and more of the new designs incorporate detailed analysis methods (which use fracture mechanics) [6].

The material resistance to fatigue failure primarily depends on the characteristics of detail/joint geometry, material chemical composition and mechanical properties, and the service environment. The material resistance is typically determined in laboratory tests by the application of constant amplitude stress cycle on various detail/joint geometries until fatigue failure occurs. By carrying out similar tests for different stress amplitudes a relationship between the stress amplitude, $S$, and the number of cycles, $N$, is established. The S-N curves developed for simple details (i.e., stiffener, cut-out, etc.) account for the peak stresses and can be directly used with the member nominal stresses [10] .

The application of linear elastic fracture mechanics, LEFM, in estimating the life of the structure assumes that cracks has already initiated in the material. The behaviour of the crack can be predicted under anticipated service loading. The estimated behaviour is used to schedule inspection and maintenance in order to assure that defects do not propagate to a catastrophic size [3].

\section{FRACTURE MECHANICS APPROACH}

This section provides an introduction to the important

Fatigue Analysis

Fracture Mechanics

S-N Curve

Hybrid SN-FM

Nominal Stress

Hot-Spot Stress

Notch Stress

Notch Strain

Fig. 1 Fatigue Analysis Techniques 
aspects of linear elastic fracture mechanics (LEFM) and shows how it can be used to describe and predict fatigue crack growth rate and fatigue life. It provides a general background for the concepts of fracture mechanics and numerical tools needed for fatigue design involving crack growth and fracture analysis. The basic control factors in fracture mechanics are the stress intensity factor $K$, the energy release rate $G$, the crack opening displacement $C O D$, and the J-integral $J$. These quantities along with their critical or limiting values are the foundation of any fracture analysis [7].

\section{LEFM CONCEPTS}

Fracture mechanics is used to evaluate the strength of a structure or component in the presence of a crack or flaw. Its application to fatigue involves the crack growth process, covering the range from a detectable crack or flaw to final fracture. One of the common methods used to analyze this process is LEFM. The method is used to determine crack growth in materials under the basic assumption that material conditions are predominantly linear elastic during the fatigue process. For crack growth or fracture conditions that violate this basic assumption, elastic-plastic fracture mechanics approaches are used to describe the fatigue and fracture process. It is necessary to define the basic crack surface displacement modes by which a crack can extend before using LEFM concepts for the crack growth analysis [11].

\section{MODES OF CRACK EXTENSION}

Fig. 2 shows three modes by which a crack can extend.

- Mode I is the opening (tensile) mode where the crack surfaces move directly apart ;

- Mode II is the sliding (in-plane shearing) mode where the crack surfaces slide over one another in the direction perpendicular to the leading edge of the crack;

- MODE III is the tearing (anti-plane shear) mode where the crack surfaces move relative to one another and parallel to the leading edge of the crack.

\section{FATIGUE CRACK GROWTH BASED ON LEFM}

The main goal of the application of fracture mechanics in fatigue analysis is to estimate the total number of cycles for the assumed initial crack $a_{i}$ to reach a final length $a_{f}$ The crack tip stress intensity factor is an extremely useful parameter to address crack growth behaviour as long as the bulk of the material is elastic and plastic deformation is limited to a small region at the crack tip [12] .

In order to illustrate the basic parameters of the fatigue crack growth, Fig. 3 shows a typical plot of crack propagation where it is noticed that:

- Crack length increases with the increasing number of loading cycles;

- Crack growth rate most often increases with increasing crack length;

- Crack growth rate increases with increasing stress level;

- Crack becomes longer at an increasingly rapid rate;

- Most of the loading cycles involved in the total life of the component are consumed during the early stages of crack extension $[10,13]$.

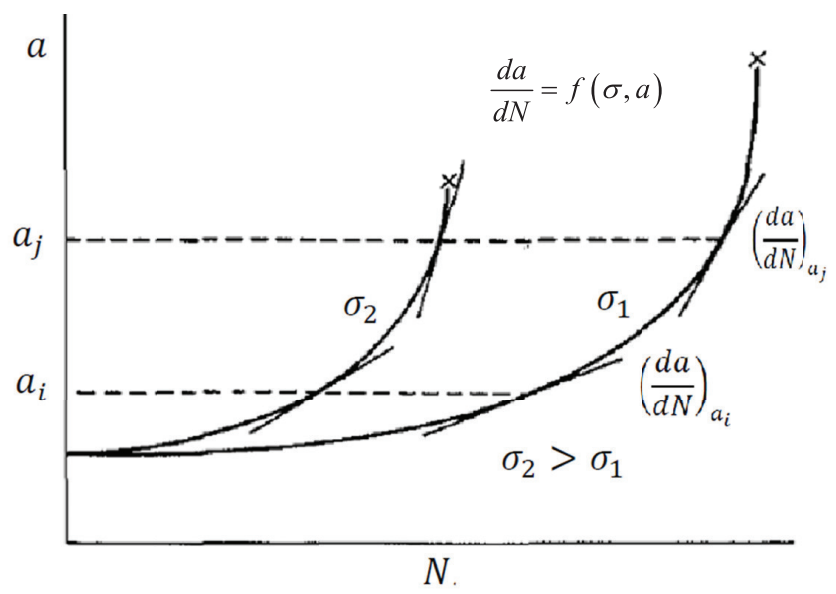

Fig. 3 Effect of crack length and stress level on crack propagation rate

In general, as shown in Fig. 4, Fig. 5 and 6 , it has been observed that the fatigue process involves the following stages:

1. Stage I - Initiation

a. Cyclic slip

b. Crack nucleation,

c. Short (micro) crack growth,

2. Stage II - Stable crack growth
a. Long (macro) crack growth, and

3. Stage III - unstable crack growth a. Final fracture.

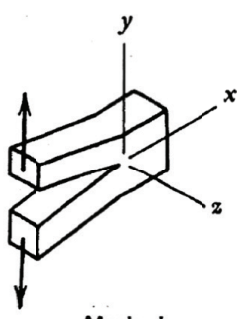

Mode I

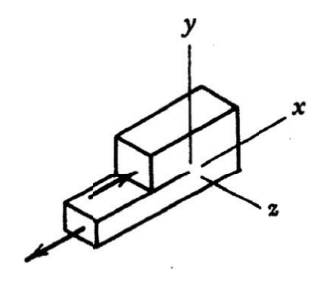

Mode II

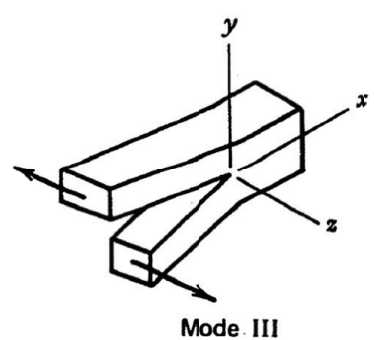

Mode. III

\section{FATIGUE ANALYSIS OF SHIP STRUCTURES}

Fatigue is responsible for a large amount of cracks occurring in welded ship structural details. For many years fatigue - related failure has become a major concern in the maintenance 


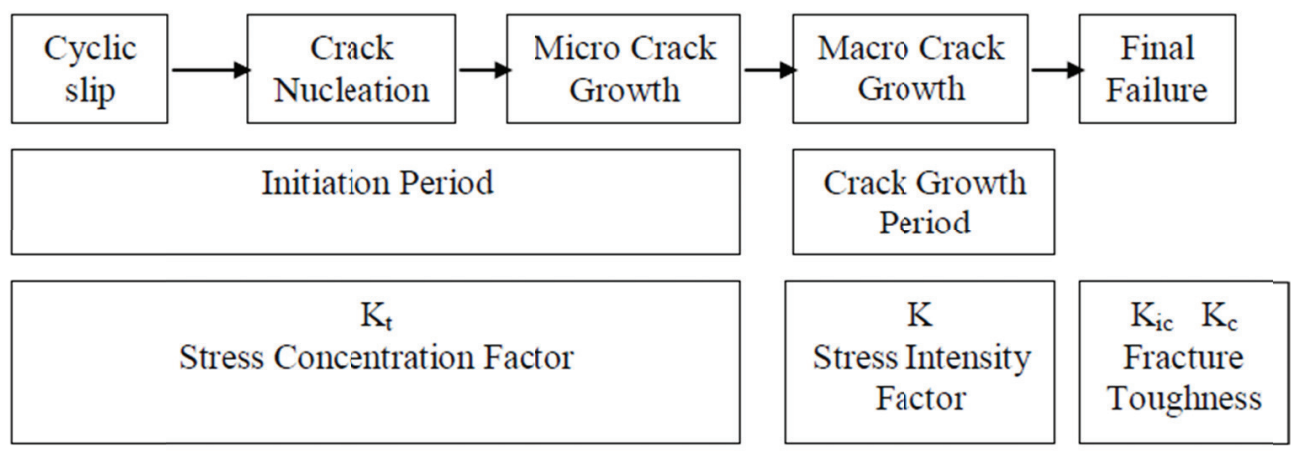

Fig. 4 Phases of fatigue cracking

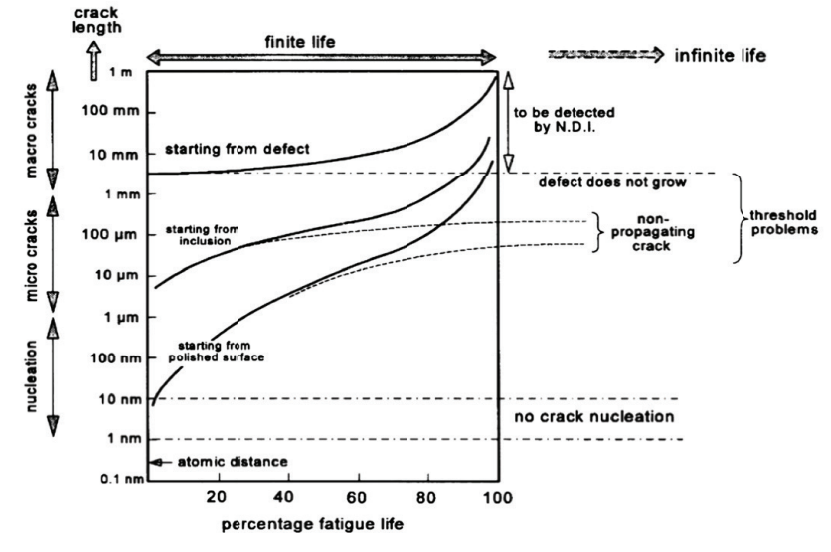

Fig. 5 Different scenarios of fatigue crack growth

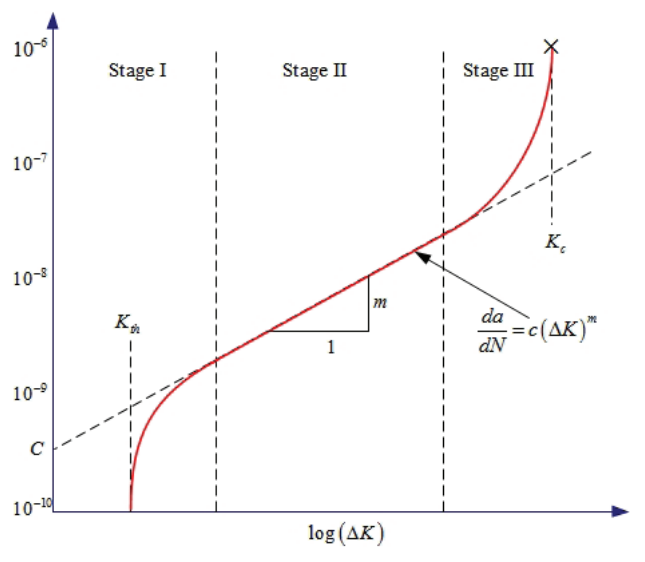

Fig. 6 Fatigue rate curve da/dN versus $\Delta K$ of existing ships and the design of new ships especially after the introduction of high tensile steel ( HTS). Numerous cracks were experienced by relatively new oil carriers constructed of HTS materials. The cracks were discovered when the ships were about 3 to 4 years old without any significant corrosion or wastage $[1,14]$.

The main factors affecting increased number of fatigue cracks in ships may be summarized as follows:

1. The trend of reducing the ship scantlings based on detailed stress analysis and the increased use of HTS, has resulted in the increase of the general stress level. Note that improved detail design which would cause a reduction of the SCF value for ship structural details, has minimized the effect of increased stress level [4, 14].

2. Tankers operate on trade routes (e.g., TAPS trade route from California to Alaska) having severe weather for the majority of their operational time, which causes very severe loading with respect to fatigue damage.

3. The presence of corrosion (general, pitting, and grooving) in ballast and cargo tanks resulting in a reduction of the fatigue life of ship structural details [4] .

Due to the growing number of fatigue cracks a more direct control of fatigue is needed. The aim of the fatigue control is to ensure that all parts of the hull structure subjected to fatigue (dynamic) loading have an adequate fatigue life. Calculated fatigue lives, calibrated with the relevant fatigue damage data, may give the basis for the structural design (steel selection, scantlings and local details). Furthermore, they can form the basis for efficient inspection programs during fabrication and throughout the service life of the structure. [14]

\section{AREAS SUSCEPTIBLE TO FATIGUE DAMAGE}

Fatigue damages are known to occur more frequently for some ship types and categories of hull structure elements. The fatigue life is in particular related to the magnitude of the dynamic stress level, the corrosiveness of the environment and the magnitude of notch and stress concentration factors of the structural details, which all vary depending on ship type and structure. The importance of possible fatigue damage is related to the number of potential damage points of a considered type for the ship or structure in question and to its consequences. [14]

In ship structures a major fraction of the total number of fatigue damages occurs in panel stiffeners on the ship side and bottom and on the boundaries of ballast and cargo tanks [14] .

Fig. 7 and 8 show a possible distribution of fatigue cracks in a typical ship structural component. In tankers, cracks occur mostly on the side longitudinals at the connections to transverse bulkheads or transverse webs. Other ship types such as bulk carriers also suffer from fatigue cracks. Where in some bulk carriers, cracks were commonly found in the hard corners of the lower hopper tanks connecting to the 
side frames, and the lower stools connecting to the double bottom [1] .

DNV [14] and other classification societies has published some tables showing the critical areas for different ship types. As an example for tankers Tab. 1 is listed hereunder.

Tab.1 Critical details for a tanker

\begin{tabular}{|c|c|c|}
\hline Structure member & Structural detail & Load type \\
\hline $\begin{array}{l}\text { Side, bottom and } \\
\text { deck plating and } \\
\text { longitudinals }\end{array}$ & $\begin{array}{l}\text { Butt joints, deck openings } \\
\text { and attachment to trans- } \\
\text { verse webs, transverse } \\
\text { bulkheads, hopper knuckles } \\
\text { and intermediate longitudi- } \\
\text { nal girders }\end{array}$ & $\begin{array}{l}\text { Hull girder bending, stiffen- } \\
\text { er lateral pressure load and } \\
\text { support deformation }\end{array}$ \\
\hline $\begin{array}{l}\text { Transverse girder and } \\
\text { stringer structures }\end{array}$ & $\begin{array}{l}\text { Bracket toes, girder flange } \\
\text { butt joints, curved girder } \\
\text { flanges, knuckle of inner } \\
\text { bottom and sloped hopper } \\
\text { side and other panel knuck- } \\
\text { les including intersection } \\
\text { with transverse girder webs. } \\
\text { Single lug } \\
\text { slots for panel stiffeners, } \\
\text { access and lightening holes }\end{array}$ & $\begin{array}{l}\text { Sea pressure load combined } \\
\text { with cargo or ballast pres- } \\
\text { sure load }\end{array}$ \\
\hline $\begin{array}{l}\text { Longitudinal girders } \\
\text { of deck and bottom } \\
\text { structure }\end{array}$ & $\begin{array}{l}\text { Bracket terminations of } \\
\text { butting transverse members } \\
\text { (girders, stiffeners) }\end{array}$ & $\begin{array}{l}\text { Hull girder bending, and } \\
\text { bending / deformation } \\
\text { of longitudinal girder } \\
\text { and considered abutting } \\
\text { member }\end{array}$ \\
\hline
\end{tabular}

\section{PROPOSED PROCEDURES APPLICABLE TO CUT-OUTS}

A calculation method applied to a cut-out model in a side connection of a crude oil carrier, is proposed. The model encompasses a longitudinal stiffener passing through a side transverse. Due to the cut-out introduced in the side transverse this connection is suspected of fatigue failure [15].

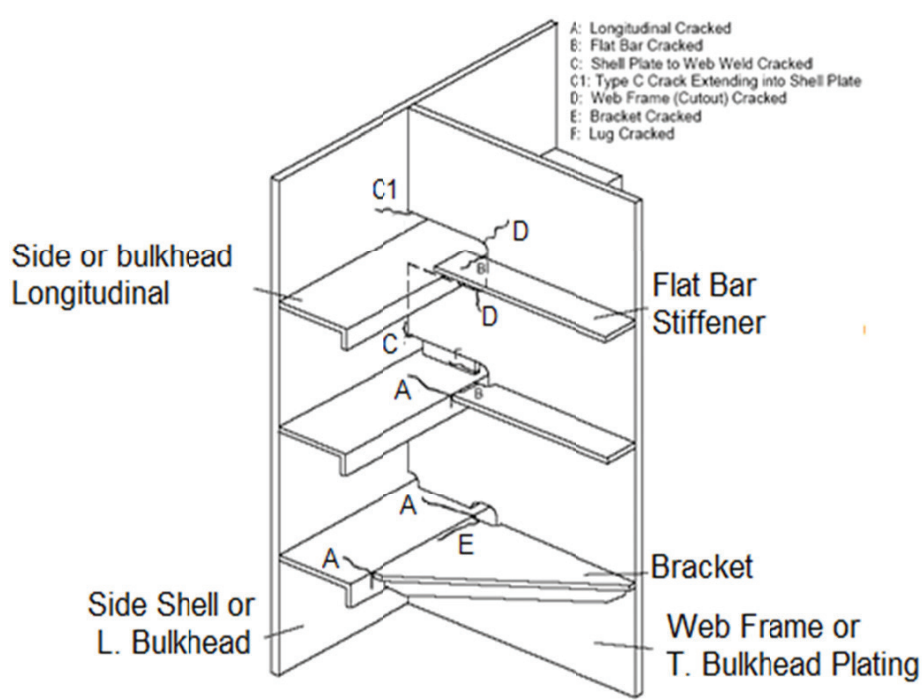

Fig. 7 Distribution of ship's fatigue cracks
Also, the following assumptions are used for the analysis of the finite element model:

- Material is isotropic;

- Linear fracture mechanics applies;

- the plastic zone in the crack front is minimal.

ABAQUS built- in features can only be used to analyze a static crack (i.e. in-site crack) or a propagating crack through a predefined path. The case of crack propagation through a predefined path is practical for the analysis of laminations (i.e. fibre glass reinforced composites). However, in case of fatigue crack propagation through ship structural details the path of the crack is unknown. Hence, because of limitation of this software a special script is developed with the purpose of analyzing a propagating crack without having predefined path.

The simplest way to explain this idea is that a static crack will be first analyzed and from the analysis the crack propagation direction is made known and then the crack is propagated in this direction. Another static crack will be analyzed in the new location until the crack is terminated.

\section{MODELLING THE ORIGINAL, NON- CRACKED ELEMENT MODEL}

The original model is analyzed by using the finite element method to indicate the critical point, i.e. the point where maximum stresses occur and where the crack is suspected to start. The modelling technique, meshing and loading of the original model is discussed below.

\section{MODELLING THE GEOMETRY}

The crack analysis can be carried out by using either $2 \mathrm{D}$ or 3D models. For each model either shell or solid elements

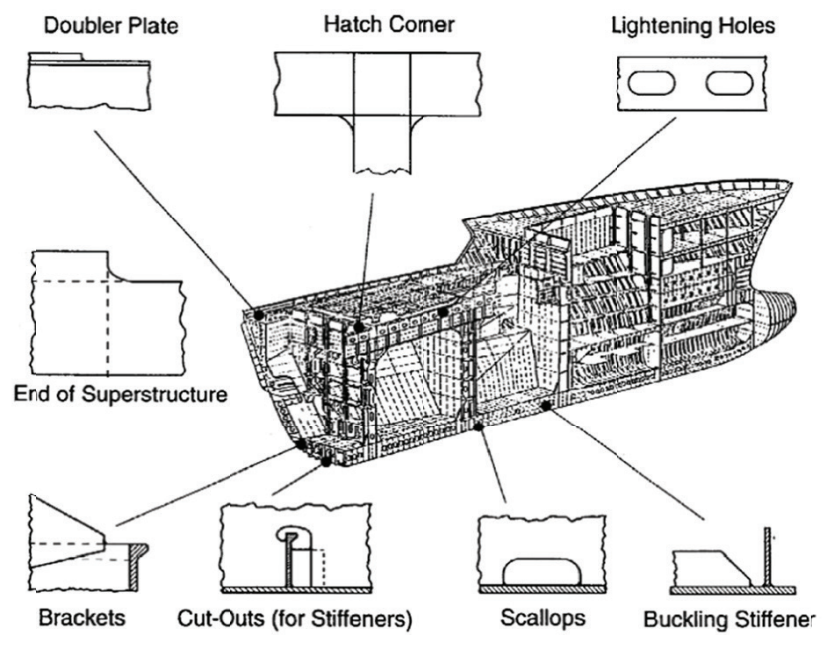

Fig. 8 Critical structural details 


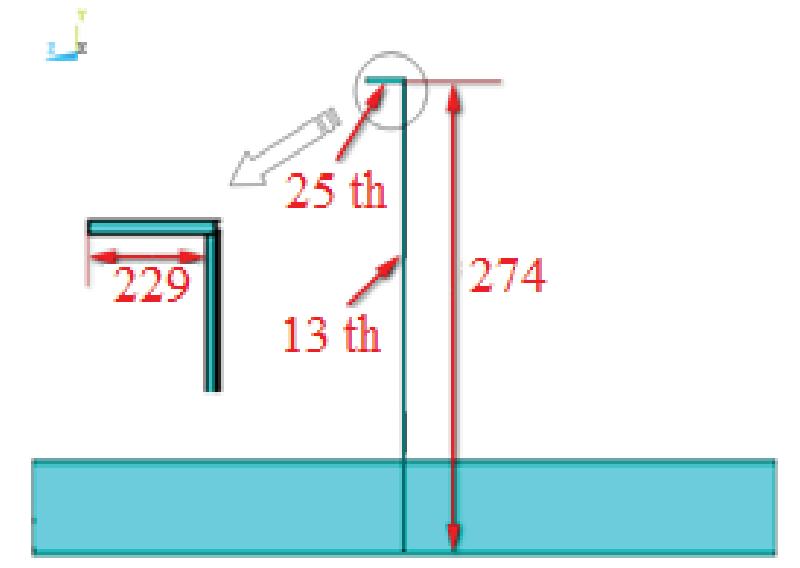

Fig. 9 Model dimensions

can be used. The modelling by using shell and continuum elements can be applied to analyzing fully through cracks, e.g. a cracked plate. However continuum elements cannot be used for 3D modelling. The solid modelling has the advantage of analyzing both fully through cracks and partially through cracks, e.g. penny cracks in shafts [16]. Fig. 9 and 10 show model dimensions in two views.

Since most cracks in the ship structures will be fully through ones, hence the using of shell elements will be much easier than solid elements with no reduction in the quality of the analysis. This also helps reducing the programming used in propagating cracks and reduces the time required for the analysis. The proposed element is that of four nodes, S4, which can be degenerated into a triangle to allow the account of crack tip singularity. The area around the cut-out in the web frame, with estimated high stress concentration, will be meshed by using a finer mesh as shown in Fig. 11 and 12.

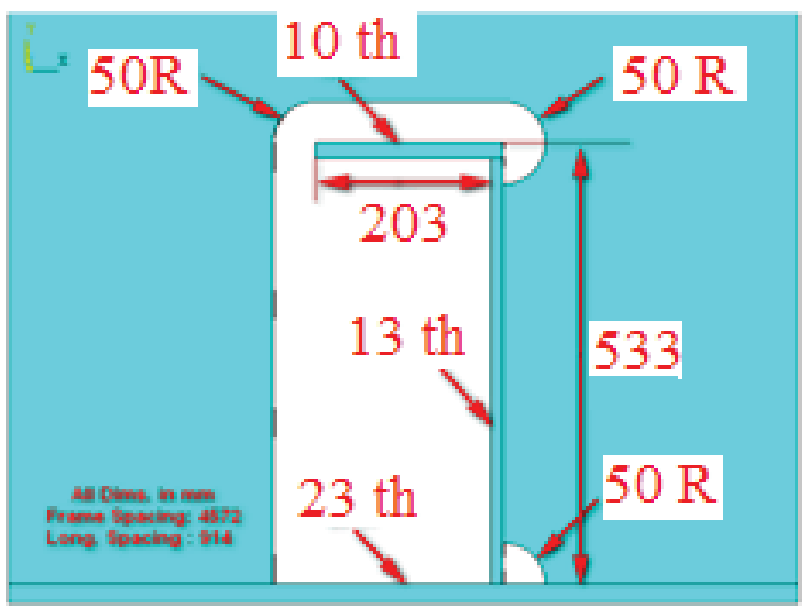

Fig. 10 Model dimensions

After several trials by using both medial axis and advancing front meshing algorithms, the advancing front meshing algorithm was selected for this analysis. The medial axis meshing algorithm is much faster than the advancing front meshing algorithm, especially with the repeated re-meshing. However, due to sensitivity of the mesh around the crack tip, especially in the initiation phase, the mesh has to follow an exact seeding pattern which can only be achieved by using the advancing front meshing technique [17].

\section{BOUNDARY CONDITIONS}

Some studies were made to show the effect of boundary conditions on the hot-spot stress. The results showed the insensitivity of the fixation boundary conditions on the hotspot stress away from the boundary. However, boundary conditions are based on symmetry, continuity and engineering judgment. The boundary conditions applied to this analysis are shown in Fig.13, where, UX, UY and UZ are the translation

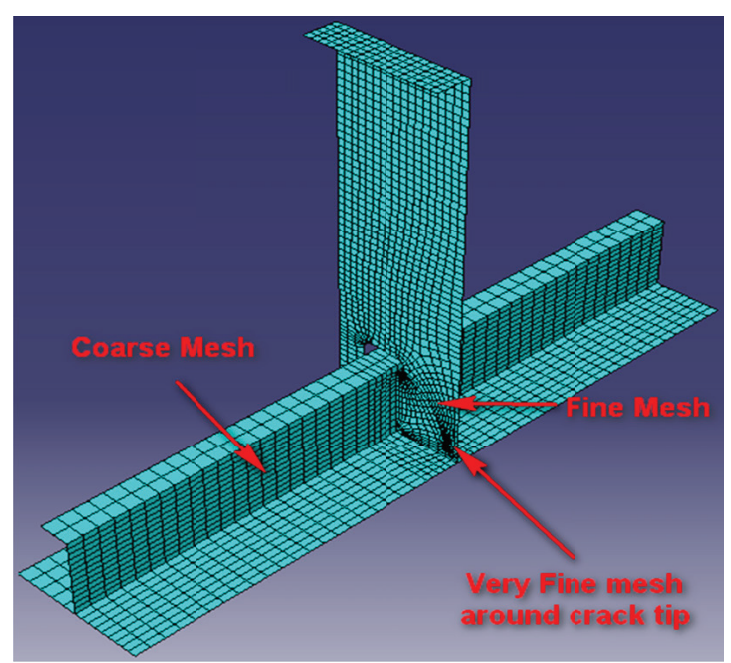

Fig. 11 Different mesh sizes

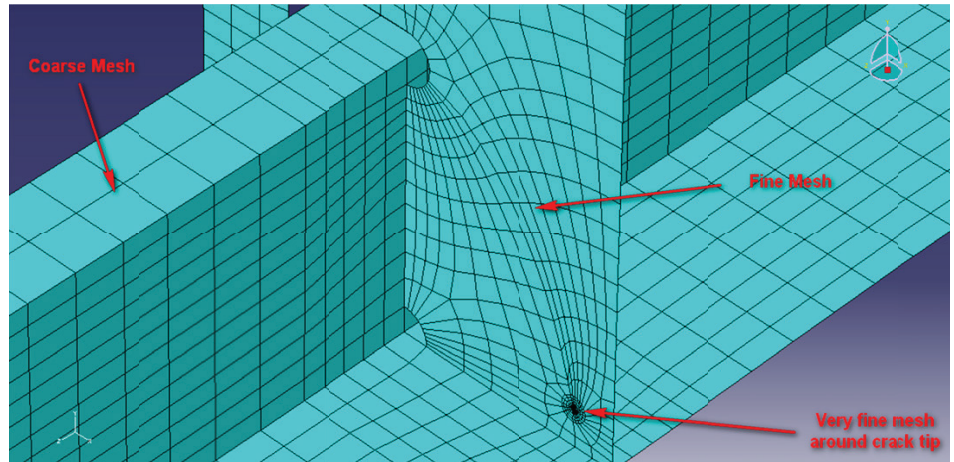

Fig. 12 Different mesh sizes 
in $\mathrm{X}, \mathrm{Y}$ and $\mathrm{Z}$ directions, respectively, and ROTX, ROTX and ROTX are the rotation about $\mathrm{X}, \mathrm{Y}$ and $\mathrm{Z}$ axis , respectively, $[15,18]$.

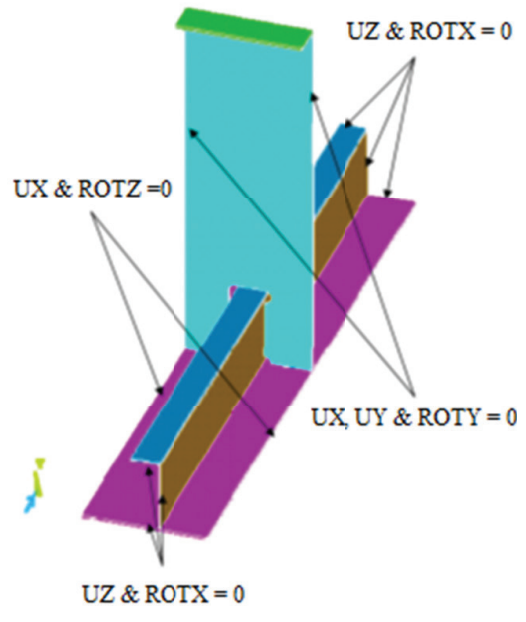

Fig. 13 FEM model boundary conditions

\section{APPLIED LOADS}

To analyze the crack propagation by using fracture mechanics the fatigue loading will be simplified as much as possible. This could be done by choosing a detail placed as close to the ship's neutral axis as possible to eliminate hull girder loads. In addition, the cargo tank will be assumed empty to eliminate internal loads. Hence, for the considered model of oil tanker's side connection, the fatigue loads playing the major role in this analysis, are those resulting from the varying sea water pressure on the outer shell.

\section{INITIAL CRACK}

\section{LOCATION OF INITIAL CRACK}

The welded structure in question will be assumed to have only one initial crack. After the analysis of the non-cracked element model the location of the maximum stresses (von Mises stress) is recorded and will represent the location for the start point of the initial crack.

\section{SIZE OF INITIAL CRACK}

As discussed before, the initial crack length can be estimated by using different methods, and to keep the estimation practical, the crack length is assumed as that of the smallest crack detectable by using X-ray NDT method; this length is equal to $3.81 \mathrm{~mm}$. [7]

\section{RESULTS OF THE INITIAL CRACK ANALYSIS}

After the analysis of the initially cracked element model, the values of $\Delta K_{I}$ and $\Delta K_{I I}$ are obtained directly by applying the finite element model. The fatigue crack growth rate has been expressed by Tanaka [20] who used a Paris type equation as a function of an effective stress intensity factor:

$$
\frac{d a}{d N}=C\left(\Delta K_{e f f}\right)^{m}
$$

where the effective stress intensity factor range $\Delta K_{\text {eff }}$ for combined mode -I -and- II loadings is expressed by:

$$
\Delta K_{e f f}=\left(\Delta K_{I}^{4}+8 \Delta K_{I I}^{4}\right)^{\frac{1}{4}}
$$

\section{INTRODUCTION OF A NEW CRACK SEGMENT}

After the analysis of the initial crack and determining the value of the crack extension angle $\hat{\theta}$, a new crack extension segment with the length $d a$ is introduced. The $d a$ - length is not an essential value for the analysis, however a smaller $d a$ value will lead to better numerical integration for the fatigue life. And of course the smaller the value the more calculation processes are needed and hence the time to complete a full analysis.

One major problem that occurs when selecting a relatively large length $d a$ is that the meshing becomes impossible sometimes. This is due to the big difference between the seed values of the lines representing the start of the crack, see Fig. 14 below.
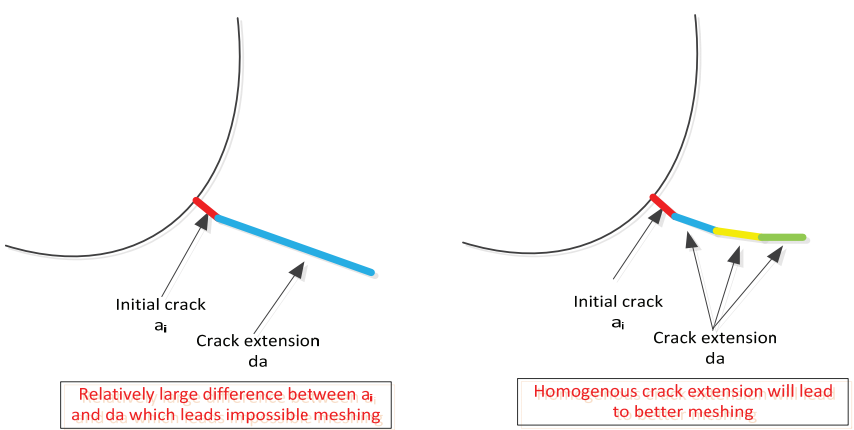

Fig. 14 Different values of the crack extension da

\section{ANALYSIS OF THE CRACKED ELEMENT MODEL AFTER EXTENSION}

The analysis of the model after each crack extension is continued and all relevant values are stored for each step of the crack extension. The most important parameters are : a, $\Delta K_{I}, \Delta K_{I I}, \Delta K_{e f p} \hat{\theta}$.The event of $\Delta K_{e f f}>K_{C}$ means that the crack will continue to propagate under Paris' law. Hence a new crack segment is introduced and analyzed, as stated previously in 6.4.

This analysis continues until the effective stress intensity 
factor $\Delta K_{\text {eff }}$ reaches its maximum value which is equal to the value of the critical stress intensity factor $K_{C}$. The event of $\Delta K_{\text {eff }}>K_{C}$ means that the stage II of stable crack growth have ended and Paris law is no more applicable. The crack size a at this stage, can be considered the critical crack size, $a_{c}$.

As discussed before, after reaching this value the crack propagation enters stage III where the crack propagates at very high speed and will not affect the fatigue life calculation. Hence, at this stage the analysis can be ended without any compromise in the calculation of the fatigue life of the model.

Another important check which must be programmed is to check that each time a new crack segment is introduced and the end of this crack segment still remains within the domain of the model. Unless this quite simple check is programmed the program may never terminate if the variable load is small and the model is completely cracked without reaching the condition of $\Delta K_{e f f}>K_{C}$.

\section{FATIGUE LIFE CALCULATION}

The fatigue life calculation can be accomplished in two stages. First, the number of fatigue load cycles required to propagate the crack from the initial size $a_{i}$ to the final size $a_{f}$ This can be done by integrating Paris formula, as discussed below. The second step is to estimate the number of fatigue load cycles that occur each year for a ship. This way the calculated number of cycles from the first step can be translated into number of years .

\section{NUMBER OF CYCLES TO FAILURE}

At the end of the calculations and after the value of the range of effective stress intensity factor $\Delta K_{\text {eff }}$ exceeds the value of the critical stress intensity factor $K_{C}$, the fatigue life, as number of cycles to failure, can be calculated by using numerical integration of Paris law, as discussed in 6.3.

$$
\frac{d a}{d N}=C(\Delta K)^{m}
$$

$$
\text { Fatigue Life }=\int_{0}^{N} d N=\frac{1}{C} \int_{a_{i}}^{a_{f}} \frac{d a}{(\Delta K)^{m}}
$$

In the discussed analysis method the step at which crack propagates , $d a$, is held constant all over the analysis. Also the material constants $C$ and $m$ are kept constant. Hence the above mentioned integration can be simplified into a very simple summation as follows:

$$
N=\frac{d_{a}}{C} \sum_{a_{i}}^{a_{f}} \frac{1}{(\Delta K)^{m}}
$$

The limitation of the Paris law is that it is only capable of describing data in Stage II (see Fig. 6). If the data exhibits a threshold (Stage I) or an accelerated growth (Stage III) Paris law cannot adequately describe these regions. Depending upon the analysis being undertaken, this approximation may not be adequate. Finally, the Paris law does not consider the effect of stress ratio and it depends upon the used material. For steels tested at various stress ratios, a family of straight lines parallel to each other is produced. This means that the value of $m$ is the same for all stress ratios but the value of $C$ is specific for a particular stress ratio.

\section{FATIGUE LIFE}

As indicated in Bureau Veritas rules [19] the number of cycles for the expected ship's life Nt can be estimated by using the following equation:

$$
N_{t}=\frac{\alpha_{o} T}{4 \log L}
$$

where: $\mathrm{T}$ is the design life in seconds, $\mathrm{L}$ is the length of the ship, $\alpha_{o}$ is the sailing factor which takes into account the time needed for loading/unloading operations, repairs, etc. As a rule, $\alpha_{o}$ may be taken equal to 0.85 .

Calculating the number of cycles corresponding to a crack length or final failure, knowing the number of cycles by using crack propagation analysis as stated before, the previous relation could be used accordingly, to estimate the time (e.g. number of years) corresponding to each stage of the crack growth.

$$
\begin{array}{ll}
T=\frac{4 \log L}{\alpha_{o}} N=4.71 \times \log L \times N & \rightarrow \mathrm{T} \text { in seconds } \\
T=1.492 \times 10^{-7} \times \log L \times N & \rightarrow \mathrm{T} \text { in years }
\end{array}
$$

Finally, by using the assumptions of number of load cycles per year, the life of the ship can be calculated. Also the following graphs can be plotted:

- Crack profile;

- $\Delta K_{e q}, \Delta K_{I}$ and $\Delta K_{I I}$ versus crack length $a$;

- $\Delta K_{e q}, \Delta K_{I}$ and $\Delta K_{I I}$ versus time;

- Crack length $a$ versus time;

\section{RESULTS}

After the successful running of the developed program shown in the flow chart of Fig. 15, the results of the analysis could be presented as follows:

A crack will initiate at the scallop of the cut-out in the web frame due to increased stresses at this area. This crack will start propagating towards the side shell plating due to fatigue loading. The total life of the model was calculated to be 7.8 years. The illustration of the crack propagation during the fatigue life of the model is illustrated in the form of graphs and crack profiles for different stages of the crack propagation. Tab. 2 shows the summary of the different phases. 


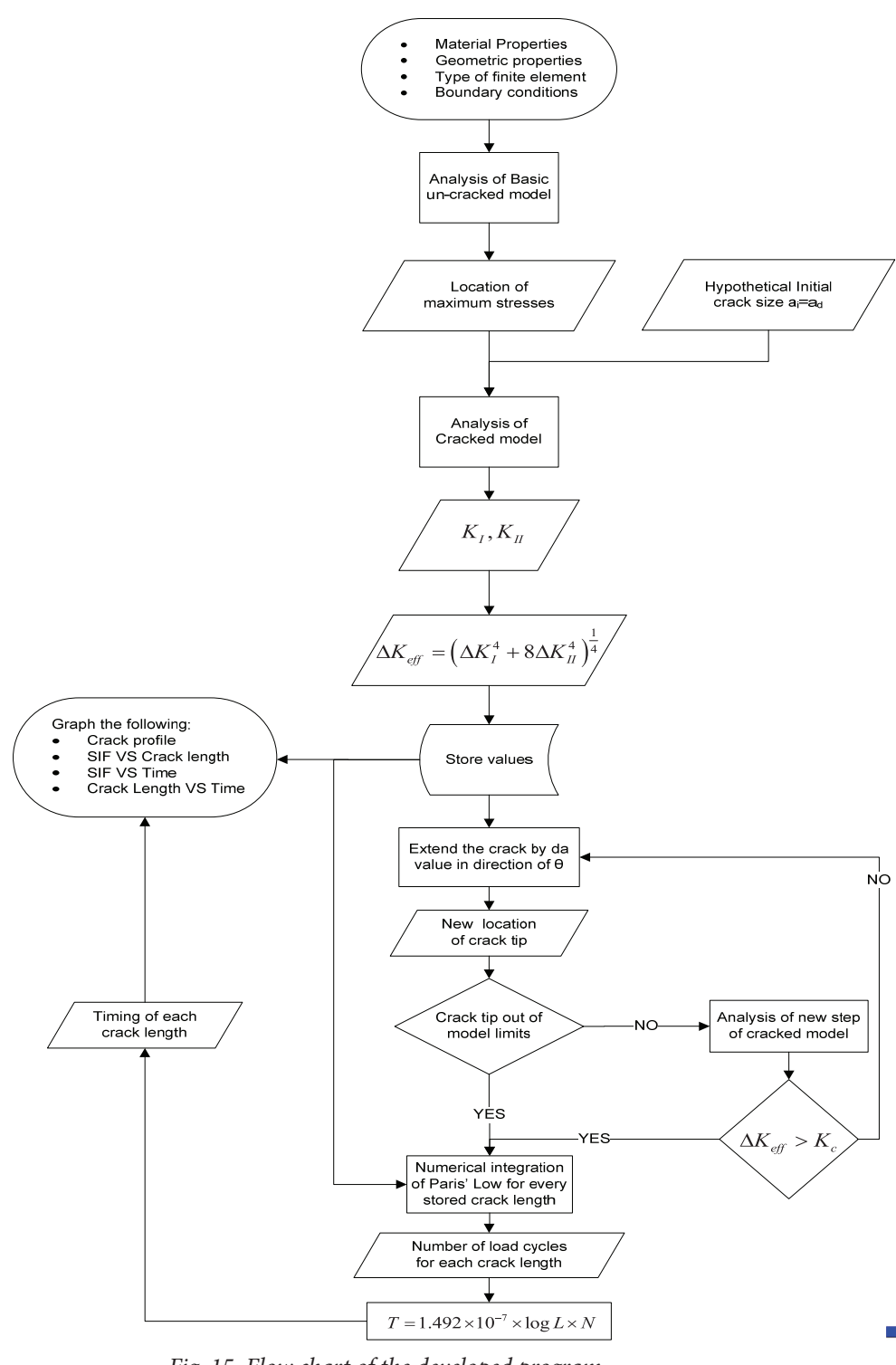

Fig. 15 Flow chart of the developed program

Tab. 2 Summary of crack propagation

\begin{tabular}{|l|l|l|l|l|}
\hline \multirow{2}{*}{ Figure } & \multicolumn{2}{c|}{ Crack length } & \multicolumn{2}{c|}{ Time } \\
\cline { 2 - 5 } & $a(\mathrm{~mm})$ & $\% a_{f}$ & T (years) & $\%$ Life \\
\hline Fig. 16 & 3.81 & $0 \%$ & 0 & $0 \%$ \\
\hline Fig. 17 & 39.81 & $6 \%$ & 1.9 & $25 \%$ \\
\hline Fig.18 & 99.81 & $15 \%$ & 3.9 & $50 \%$ \\
\hline Fig. 19 & 163.81 & $25 \%$ & 5.5 & $70 \%$ \\
\hline Fig. 20 & 183.81 & $28 \%$ & 5.8 & $75 \%$ \\
\hline Fig.21 & 323.81 & $50 \%$ & 7.3 & $93 \%$ \\
\hline Fig. 22 & 487.81 & $75 \%$ & 7.7 & $98 \%$ \\
\hline Fig. 23 & 647.81 & $100 \%$ & 7.8 & $100 \%$ \\
\hline
\end{tabular}

\section{CRACK PROFILE AND STRESS FIELD}

The stress field shown in Fig. 24 illustrates the distribution of the stresses around the crack tip. The red area in the region indicates where the stress is higher than the yield stress of the material.

\section{CRACK LENGTH VERSUS TIME}

Fig. 25 shows that the crack starts propagating at a relatively very low rate. As an example, $25 \%$ of the fatigue life is consumed to propagate the crack for only $6 \%$ of its final length. However the rate increases rapidly after reaching about $50 \%$ of the fatigue life. Also, it shows that the last $50 \%$ of the crack length is consumed rapidly in less than $7 \%$ of the total life.

\section{EQUIVALENT STRESS INTENSITY FACTOR VERSUS CRACK LENGTH AND TIME}

Fig. 26 shows that the equivalent stress intensity factor $\Delta K_{e q}$ increases steadily during the crack propagation phase while increases rapidly at the final stages. This shows that the $\Delta K_{e q}$ follows Paris law during stage II of the propagation phase .

In combination with Fig. 26, Fig. 27 shows that during stage II of the propagation phase, where the $\Delta K_{e q}$ follows Paris law, the $\Delta K_{e q}$ increases by the increasing of the crack size. However, at the final stages it decreases with the increase of crack size. This shows that the analysis is only valid for the propagation period because the developed programs is only applicable to the area following Paris law and does not include formulas for stage III of the crack propagation.

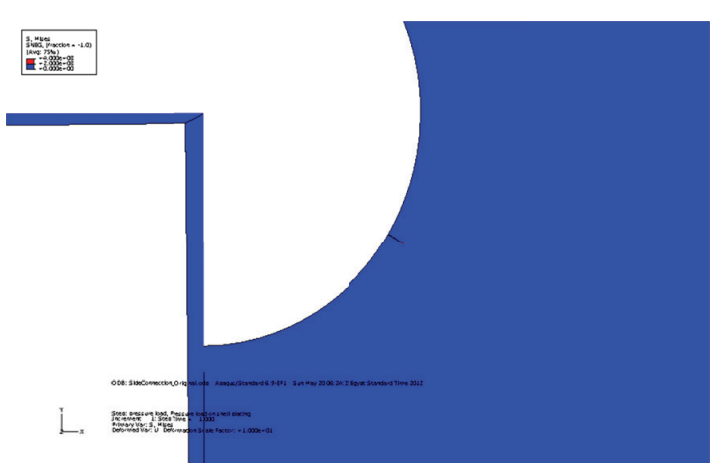

Fig. 16 Initial crack profile

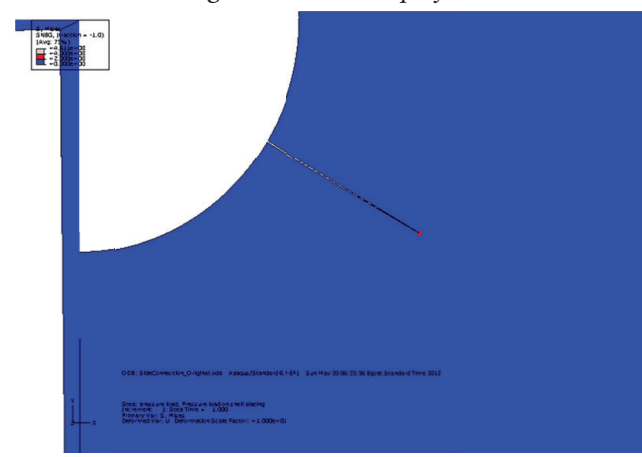

Fig. 17 Crack profile

$a=39.81 \mathrm{~mm}=6 \% a_{f} t=1.9$ Years $=25 \%$ Life 


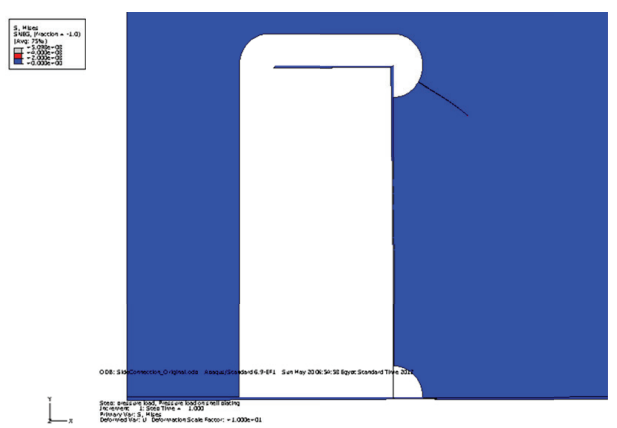

Figure 18 - Crack Profile $a=99.81 \mathrm{~mm}=15 \% a_{f} ; t=3.9$ Years $=50 \%$ Life $)$

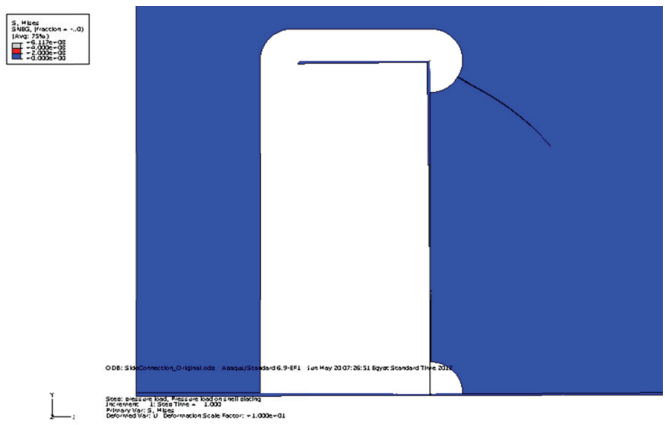

Figure 20- Crack Profile

$\left(a=183.81 \mathrm{~mm}=28 \% a_{f} ; t=5.8\right.$ Years $=75 \%$ Life $)$

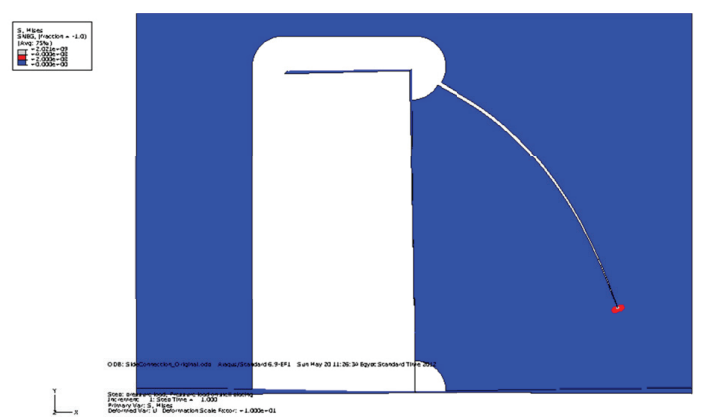

Figure 22 - Crack Profile

$a=487.81 \mathrm{~mm}=75 \% a_{f} ; t=7.7$ Years $=98 \%$ Life $)$

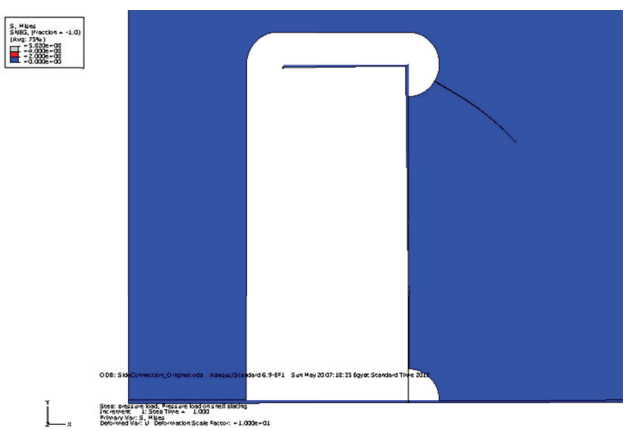

Figure 19 - Crack Profile $a=163.81 \mathrm{~mm}=25 \% a_{f} ; t=5.5$ Years $=70 \%$ Life)

灌梳

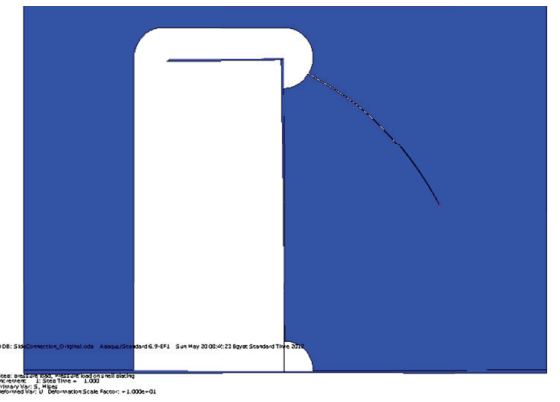

Figure 21 - Crack Profile $\left(a=323.81 \mathrm{~mm}=50 \% a_{f} ; t=7.3\right.$ Years $=93 \%$ Life $)$

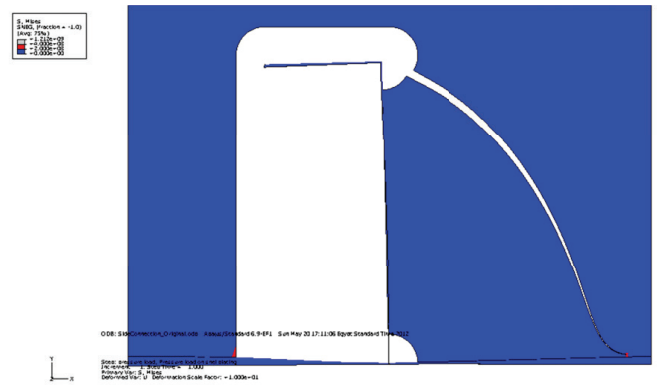

Figure 23 - Final Crack Profile $a=647.81 \mathrm{~mm}=100 \% a_{f} ; t=7.8$ Years $=100 \%$ Life $)$

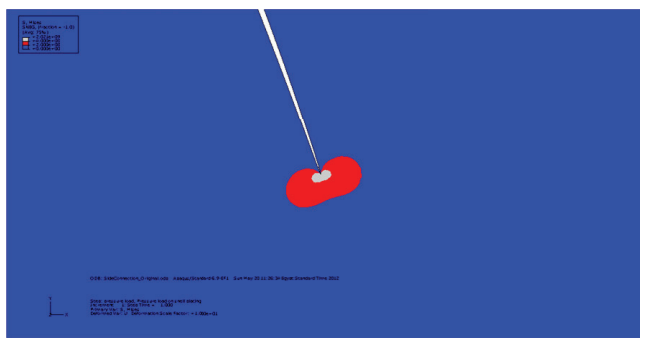

Figure 24 - Crack tip stress field 


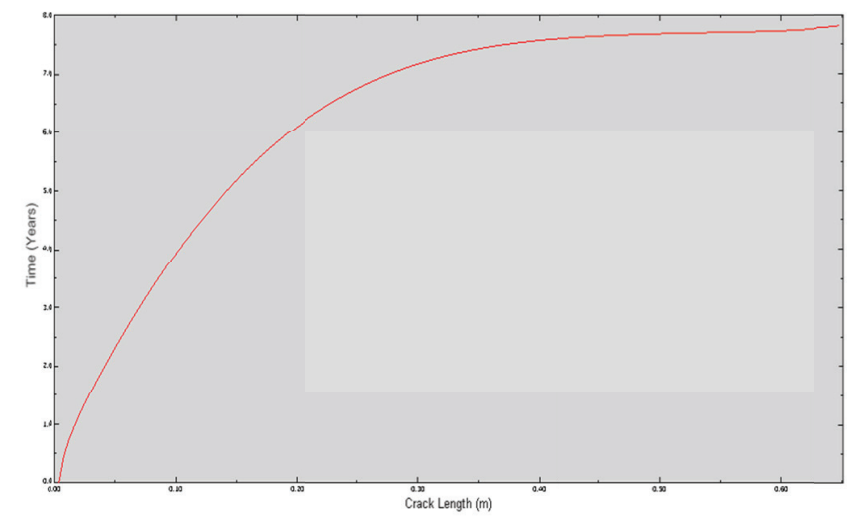

Figure 25 - Time VS Crack Length

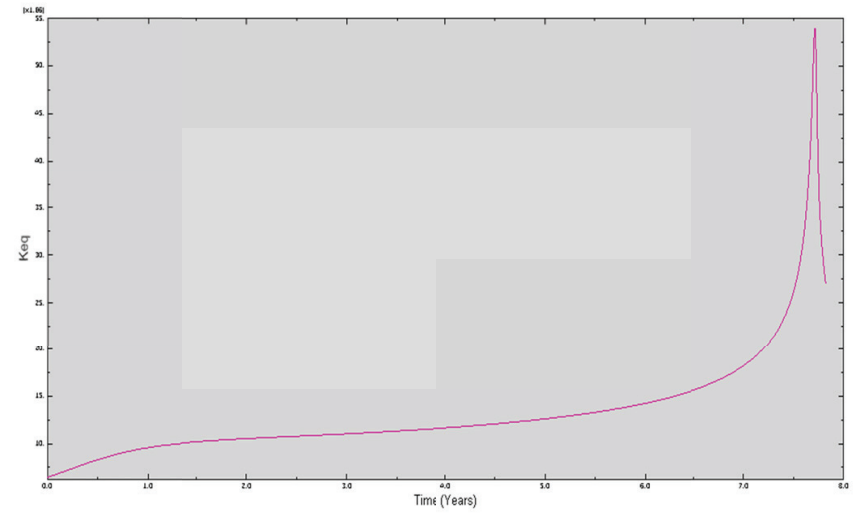

Figure 26 - $K_{\text {eq }}$ VS Time

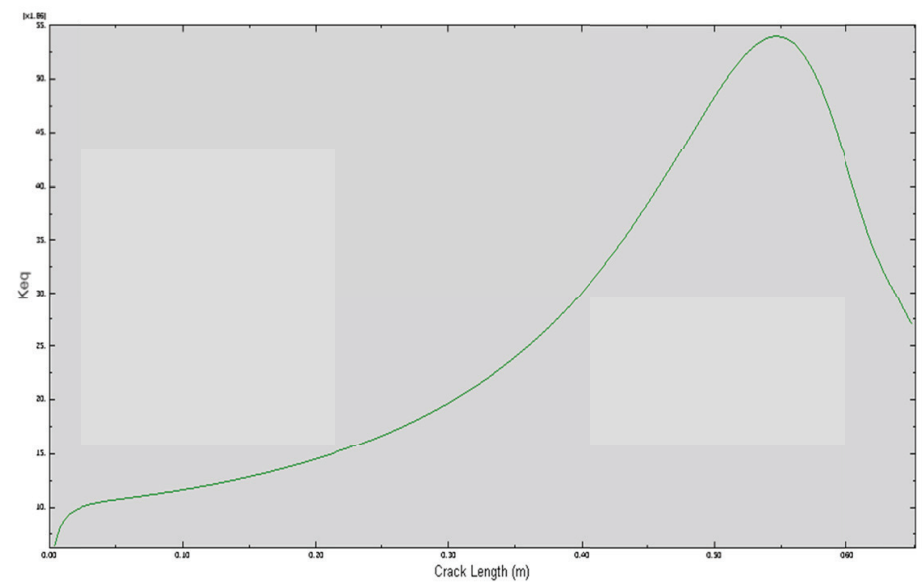

Figure 27 - $K_{\text {eq }}$ VS Crack length

\section{CONCLUSIONS}

1. The fatigue durability of ship structural details is achieved not only by careful initial design but also by a proper construction and an effective inspection, maintenance and repair program.

2. FEM is a very cost- effective tool for structural analysis which saves a lot compared to physical model testing. However, FEM cannot substitute physical testing since the results from FEA should be verified by using physical models. However application of FEM reduces the number of physical models to be tested hence also the cost of the analysis.

3. The developed program is used for the fatigue analysis of a side connection of a tanker. It uses basic programming and features of ABAQUS software package. A more complicated and generic programs can be derived by applying the same methodology for the analysis of other models.

4. Crack propagation analysis for ship structural details helps scheduling the inspection programs (locations and period) for such parts of the ship, e.g. close-up survey for tankers.

5. Fatigue analysis of the ship connections and details is very important because designing a ship that would not suffer fatigue, i.e. in the case of $\Delta K \leq \Delta K_{t h}$, is highly impractical. The lightweight of the ship will be then increased exponentially, reducing her deadweight. In addition, the added material will increase the initial cost of building the ship.

6. All of the above mentioned side effects could be avoided by carefully designing the ship structural details vulnerable to fatigue damage.

7. Immediate repair and docking delay the delivery of cargo and decrease the profit from this ship.

8. The ships that usually encounter fatigue problem are large tankers and bulk carriers. Hence, in the most extreme cases where the cracks are left without inspection or repair, the situation may lead to leakage of oil or hazardous fluids into the sea causing environmental problems.

9. Finally, the most effective way is to conduct an overall fatigue analysis for any new design of tankers or bulk carriers. As a result of such analysis the schedule of inspection of critical details can be determined. In this case, the high initial cost and loss of deadweight can be avoided, moreover the critical parts where fatigue cracks may occur are in advance determined 
before their growing into catastrophic cracks. On the contrary, if fatigue analysis was not conducted, this may lead to cracks in different high - stressed spots. If the cracks are not repaired in a satisfactory manner, they may lead to damage of ship members

\section{BIBLIOGRAPHY}

1. B. Ayyub, et al. : Risk-informed inspection of marine vessels. Ship Structures Committee, SSC-421, 2002.

2. R. Bea: Maintenance of marine structures: A state of the art summary. DTIC Document1993.

3. C. C. Capanoglu: Fatigue Technology Assessment and Strategies for Fatigue Avoidance in Marine Structures. Ship Structure Committee (SSC), 1993.

4. T. Xu : Fatigue of ship structural details - Technical Development and Problems. Journal of Ship Research, vol. 41, pp. 318-331, 1997.

5. S. Moaveni: Finite element analysis: theory and application with ANSYS. Upper Saddle River, N.J.: Prentice Hall, 1999.

6. Y.-L. Lee: Fatigue testing and analysis: theory and practice. Amsterdam; Boston: Elsevier Butterworth-Heinemann, 2005.

7. J. Schijve: Fatigue of structures and materials. New York: Springer, 2008.

8. International Association of Classification Societies ltd. (IACS) : Standard Wave Data . Recommendation 34, 2001.

9. Det Norske Veritas : Fatigue Strength Analysis of Offshore Steel Structures. (DNV) RP-C203 Recommended Practice-C203, 2001.

10. B. Farahmand, et al., Fatigue and fracture mechanics of high risk parts: application of LEFM \& FMDM theory. New York: Chapman \& Hall, 1997.

11. B. Farahmand: Fracture mechanics of metals, composites, welds, and bolted joints: application of LEFM, EPFM, and FMDM theory. Boston: Kluwer Academic Publishers, 2001.

12. S. Beden, et al.: Review of Fatigue Crack Propagation Models for Metallic Components. European Journal of Scientific Research, vol. 28, pp. 364-397, 2009.

13. H. A. Rothbart and T. H. Brown: Mechanical design handbook: measurement, analysis, and control of dynamic systems. 2nd Ed. New York: McGraw-Hill, 2006.

14. Det Norske Veritas : Fatigue Assessment of Ship Structures. (DNV) CN 30.7, 2010.
15. Dassault Systèmes Simulia Corp.: ABAQUS Analysis User's Manual. Dassault Systèmes Simulia Corp., 2008.

16. K. Ma and R. G. Bea: A Repair Management System for Fatigue Cracks in Ships. SNAME Transactions, vol. 103, pp. 343-369, 1995.

17. M. R. Andersen: Fatigue crack initiation and growth in ship structures. Ph. D Thesis, Department of Naval Architecture and Offshore Engineering, Technical University of Denmark, Lyngby, 1998.

18. Dassault Systèmes Simulia Corp.: ABAQUS Theory Manual. Dassault Systèmes Simulia Corp., 2008.

19. Registro Italiano Navale : Rules for the checking of the fatigue strength of ship hull structures. 1995.

20. A. Miranda, et al.: Path and life predictions under mixed mode I-Mode II complex loading. Paper presented at the International Symposium on Solid Mechanics, University of São Paulo, São Paulo, Brazil, 2007.

\section{CONTACT WITH THE AUTHOR}

Ahmed M H Elhewy

Naval Architecture and Marine Engineering Department Faculty of Engineering Alexandria University e-mail: ahmed.elhewy@gmail.com 